\title{
La ley de privatización bancaria: ¿de la privatización a la privatización?
}

Fco. Javier Ibisate

Los estados financieros del sistema bancario a finales de la década1980 ponen de manifiesto la crisis profunda del sector monetario. Conviene hablar de crisis en el doble sentido de esta expresión. La palabra crisis, objetivamente, nos indica una situación de deterioro moral, psiquico, económico, financiero... En su sentido etimológico indica un acto de reflexión, de hacer juicio o analizar las causas del deterioro resultante. El verdadero significado de hacer crítica es hacer un análisis de las causas y de bs efectos. Los efectos han sido suficientemente revelados, a veces con agresividad partidista, y también han sido analizados con serenidad y equilibrio científico. Entre los análisis extranjeros es de resaltar y recomendar la investigación presentada por (DIESCENITEC) y realizada por la misma alemana-IPC (Drs. Schmidt $R, y$ Zeitenger C.P.)'. Entre los múltiples estudios y publicaciones nacionales me permito recomendar la reciente tesis de graduación: "Análisis comparativo de la banca privada y banca nacionalizada en el Salvador: 1971-1988".2

Todos estamos de acuerdo en que la situación del sector bancario es crítica, aunque seguimos haciendo y retirando depósitos; convivimos con la crisis con ánimo de buscar soluciones a tal crisis. Por ello es conveniente adelantar unos pocos datos que nos hagan ver con sinceridad ese nivel de crisis. El monto de la mora bancaria triplica en la década: de 245.199 miles- $₫(1980)$ a 786.709 miles- $₫(1988)$ a precios corrientes. Medida en $₫$ de 1978 la mora, que ya estaba presente en la década anterior, muestra una reducción de 192.238 miles- $₫$ a 157.587 
miles- $₫$; indirectamente, esta comparación nos muestra el impacto tan fuerte de la inflación en esa década. Bajo ambas evaluaciones aparace la situación tan peligrosa de los créditos insolventes, porque la relación de la mora sobre préstamos y descuentos mantiene una proporción promedia del $17 \%$. La insolvencia del propio sector bancario también se devela en la relación de la mora sobre el patrimonio bancario, que ya en 1980 se eleva a la proporción de $174,60 \%$ y dentro de ciertos altibajos crece hasta $235,50 \%$ en 1988 . Las políticas de refinanciamiento vienen a agravar aún más la insolvencia crediticia y la insolvencia de las instituciones bancarias. El refinanciamiento, en valores corrientes, se triplica ampliamente entre 1980 (492.619 miles- $屯)$ y 1988 (1,552.131 miles- $₫$ ), aunque presenta cierta disminución medido en colones de 1978. Con ello la relación entre refinanciamiento y préstamos-descuentos evoluciona de $23,2 \%$ (1980) a $35,6 \%$ (1983) y $25,7 \%$ (1988). La situación de insolvencia bancaria crece al relacionar el monto de refinanciamiento con el patrimonio de estas instituciones de crédito; esta relación evoluciona de la siguiente manera: $272 \%$ (1980), $505 \%$ (1986) y $402,5 \%$ (1988). Adicionando el refinanciamiento a la mora encontramos que el sistema bancario, en conjunto, dispone de un-colón de patrimonio para cubrir cada seis-colones de mora-refinanciamiento en 1988. ${ }^{3}$

EI análisis de la misión IPC alemana, comentando la situación de la rentabilidad bancaria, termina con este párrafo: "En otros términos, estas instituciones se encontrarian prácticamente en la insolvencia, de aplicarse las normas bancarias habituales sobre la constitución de provisiones... Sin embargo una evaluación más realista de la eficiencia y la rentabilidad de la banca debería incluir un análisis más desagregado de la cartera de créditos, que constituye su activo más significativo. En efecto, la presencia de una importante cartera pesada, que no haya sido adecuadamente provisionada, podria falsear completamente los balances, ocultando la magnitud de las pérdidas reales". ${ }^{4}$ Por su parte el BCR, al evaluar la cartera de crédito de los bancos comerciales, resume la situación con unos pocos datos bien alarmantes: "La evaluación de la cartera de crédito de los Bancos comerciales ha permitido determinar el grado de descapitalización en que se encontraban dichos bancos, el monto de las pérdidas y la cartera a sanearse..., llegándose a establecer que: el $36,7 \%$ de la cartera de crédito de los nueve bancos comerciales era irrecuperable o de difícil recuperación; el 25,02\% eran créditos deficientes; y sólo el $38,28 \%$ podrian considerarse como créditos normales o casi normales". 5

Era conveniente introducir el análisis con unos datos estadísticos suficientes para mostrar el estado de crisis global e insolvencia bancaria. 
Es normal que estos datos generen la crítica, la disculpa y la aclaración. No todos los bancos están igualmente quebrados; no todos lo: sectores y empresas se hallan en el mismo estado de mora; no toda la culpa es de quien hace el crédito y algo hay que cargar al debe de qulen no lo regresa. Es logico que de la breve presentación del estado critico del sistema bancario en la década de los 1980 pasemos a hacer una crisis, un enjuiciamiento o análisis de las causas explicativas. La tesis del actual gobiemo y del actual modelo es privatización bancaria: Privatización versus estatización. En realidad, lo que necesita la banca es un radical saneamiento, una gestión técnica y responsable. Lo que necesita el pals es un sistema monetario que propicie su desarrollo económico y social. En consecuencia, la privatización bancaria no debe convertirse $o$ identificarse con el objetivo final de la reforma monetaria, sino que debe evaluarse como una de las altemativas para lograr ese objetivo final. El cuestionamiento tiene su base histórica: lo que caracterizo al sistema bancario, al igual que el resto del sector productivo antes de 1980, fué la privatización junto con la concentración económica. $Y$ ese modelo nunca propició el desarrollo económico y social; ni a ello colaboró el sistema bancario. Con la privatización bancaria y extrabancaria puede recuperarse la siempre permanente concentración económica. Pese al aleccionador compás de la guerra hay un fundado temor de que el proceso actual nos lleve de la privatización a la privatización.

I. Una decada de banca privada (1970-1979): mora, reflnanclamiento y credtto cpara qulén?

Aunque una década sea igual a otra década cronológicamente, la década de los 1980 sale muy mal parada tanto por lo que nos afecta la adversa coyuntura internacional como, sobre todo, por to que nos ha desequilibrado la prolongada guerra civil. Desde este punto de vista dirlamos que la banca privada gozó de apreciables ventajas comparativas en la década de 1970 . No quiere decir esto que fuera la más feliz de todas nuestras décadas, porque en ella comienzan a surgir los principales reguladores de nuestra economia. El eco de la guerra de cien horas con Honduras resuena en los diez anos siguientes; la estanflación internacional nos sacude desde 1973, mientras que las convulsiones sociales toman cuerpo y organización. En el subsuelo de la privatización y de la estatización hay fallas estructurales a considerar para no dejarnos llevar de la ley del péndulo: privatización-estatizaciónprivatlzación...

El entorno económico en que se mueve el sistema bancario privatizado es relativamente positivo. Un crecimiento real promedio del PIB 
del $5 \%$, superior al crecimiento de la población. La inversión total se multiplica por cinco en valores nominales, o se duplica a precios constantes de 1978. Con todo se percibe un cambio de proporciones: la inversión pública crece más rápidamente, en apoyo de una timorata inversión privada, hasta representar el $34,55 \%$ de la inversión total. Dada la mayor participación del Estado en la actividad económica, sobre todo a través del gasto de capital, aparece una tendencia oscilatoria en el déficit fiscal, que saltará bruscamente en 1979 hasta un 4,3\% del PIB. Las evoluciones de los precios de las exportaciones tradicionales determinan siete anos de superavit frente a tres anos de déficit en la balanza comercial. Esta mayoritaria fuente de divisas vendrá a reforzar las disponibilidades del sistema bancario privado, mientras que el saldo negativo de la partida de "errores y omisiones" (-534,7 millones de $₫$ ) anuncia el inicio de la fuga de capitales, que se desbordarla en la década de la banca nacionalizada. Se repetirá la pregunta: ¿quién descapitalizó a la banca nacionalizada? - La banca privada tuvo a su favor una secuencia favorable de siete anos con superavit de la balanza comercial, y sólo un ano final, 1979, ve iniciarse la sensible fuga de capitales. La banca nacionalizada tendrá todos estos elemenos en su contra.

El crédito suministrado por la banca privada aumenta considerablemente: de 553,9 millones- $₫$ (1970) a 2,123,5 millones- $\mathbb{c}(1979)$. La distribución del crédito refleja la estructura de los principales sectores económicos y refleja también la estructura de la propiedad del sistema de la banca privada. La participación de las tres exportaciones tradicionales (café, algodón, azúcar) en el crédito total asciende del $14 \%$ al $21 \%$ porcentaje superior al de toda la industria manufacturera, que pasa del $8 \%$ al $14 \%$, aunque inferior al tramo del comercio, por más que decline del $36,89 \%$ al $32.46 \%$. La construcción oscila alrededor del $11 \%$ a lo largo de la década.

Para evaluar el impacto social del crédito es importante fijarse en el peso económico del usuario y el tipo de garantía solicitada. De a cuerdo a la información estadistica disponible para 1979 se llega a la siguiente clasificación:

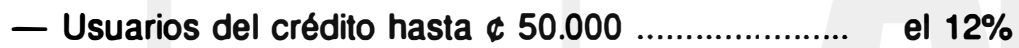

- Usuarios del crédito entre $₫ 50.000$ y $₫ 100.000 \ldots$ el $9 \%$

- Usuarios del crédito entre $₫ 100.000$ y $₫ 500.000 \ldots$ el $32 \%$

- Usuarios del crédito entre $₫ 500.000$ y más .......... el $47 \%$

"Lo anterior demuestra una alta concentración del crédito en un re- 
ducido grupo de usuarios".

De acuerdo al tamaño del usuario será el tipo de garantía requerida para el crédito. Predomina la garantía solidaria o personal, privilegio de la gran empresa, en un $56 \%$; mientras que las garantias hipotecaria y prendaria oscilen respectivamente en torno al $26 \%$ y $17 \%$. "De esto se deduce una descriminación para con el pequeno y mediano empresario, ya que estos requerian de una garantía real para la obtención de un crédito, mientras que el gran empresario disponia de mayor ventaja para el financiamiento de sus actividades, garantizadas únicamente con una promesa de pago; además de ello, en cierta manera no se aseguraba la solvencia de los bancos mediante el otorgamiento de préstamos a plazo corto, dado el alto porcentaje concedido en base a la confianza de la institución en determinados usuarios". ${ }^{\text {? }}$

De hecho, bajo el régimen de banca privada con propiedad bien concentrada, la mora creciente y el correspondiente refinanciamiento llevan al sistema bancario hasta una situación de escasa solvencia. A lo largo de la década la mora se multiplica por cinco en términos nominales: de 20.467 miles- $₫$ en 1971 a 116. 435 miles- $₫$ en 1979. Con ello la relación de la mora sobre préstamos-descuentos pasa de $6,36 \%$ a $8,15 \%$. Signo más alertador es la relación de la mora sobre el patrimonio, que en 1979 alcanza el peligroso índice de $84 \%$. Para renegociar y solventar la mora se recurre al refinanciamiento, que prácticamente triplica el monto de la mora: de 114.884 miles- $₫$ en 1971 a 321.811 miles- $₫$ en 1979. De esta manera, la relación entre refinanciamiento y préstamo-descuento sube a un $15,2 \%$, quintuplicando el límite aceptable de este indicador. La solvencia de la banca privada se torna sumamente peligrosa cuando en 1979 el monto del refinanciamiento equivale al $196 \%$ del patrimonio de dichas instituciones. Los rubros que más pesan en el refinanciamiento son, sucesivamente, el café, manufactura y la construcción. Bajo el régimen de la banca comercial privada se gestan ya los problemas de la concentración crediticia junto con la escasa solvencia institucional. "La conclusión es evidente: ya para 1971-1979 la mora y el refinanciamiento ponian en peligro al sistema bancario pues sus montos superan por amplios márgenes los límites establecidos como parámetros". ${ }^{8}$

Bajo condiciones completamente adversas, provenientes de la más contractiva coyuntura internacional, del dificitario conflicto bélico interno y de la heróica fuga de capitales privados.... la descapitalizada banca estatal llevará a límites críticos los parámetros de mora acumulada en la clientela y de insolvencia en las mismas instituciones bancarias. Sin tomar tanto en cuenta las circunctancias relativamente prósperas o 
adversas de ambas décadas comunes, silenciando que los problemas de saneamiento y de gestión técnica son comunes a esas dos épocas, resulta que el modelo y la legislación actual confunde e identifica una alternativa de política bancaria con el objetivo final de toda la reforma monetaria. El logro tinal seria el saneamieno y la tecnificación del sistema monetario-financiero, comprendida la reestructuración de la autoridad monetaria, mientras que la privatización bancaria es una estrategia alternativa, que puede funcionar bien como puede volver a funcionar muy mal en lo que se refiere al desarrollo económico y social del conjunto nacional.

\section{La politizaclón del crédito}

El concepto de "politización del crédito" tendrá aqui dos significados plenamente opuestos, y no sólo diferentes. Se dice, con toda razón, que el mercado del dinero es un mercado-politizado, porque debe estar orientado y controlado por un conjunto de objetivos y políticas que norman su comportamiento desde el quantum del flujo monetario hasta los requisitos exigibles para ser director de una institución bancaria. Con ello se subraya que la autoridad monetaria debe conjugar la técnica, la estabilidad y la honorabilidad acordes a problemas que vienen de un largo pasado hacia un mediano-largo futuro. En contraposición al técnicismo experimentado y a la honestidad probada se presenta la politización del crédito como la subordinación al partido gubernamental, a las improvistas medidas coyunturales, al juego de nombramientos por compadrazgo ideológico; en resumen, parcialización de los análisis económicos, de las medidas prácticas y de los personeros responsables de tales funciones. Se desnaturalizan las responsabilidades del Banco Central, quien lejos de ser el Banco de la Nación, Banco de Bancos y préstamista en última instancia, se convierte en la caja abierta del Estado. Se desnaturalizan las iniciativas de las instituciones de credito con sorpresivos controles. Hay que decir que la década de los 1980 ha arrastrado al sistema bancario en esta segunda dirección. Pero hay que decir toda la verdad, porque también hay politización partidista cuando se dicen medias verdades. La adversa coyuntura intemacional, aunada a la masiva fuga de capitales privados, descapitalizaron a una banca nacionalizada que, por anadidura, tuvo que absorber la mora pendiente de las décadas doradas. Sobre todo, si la guerra se convierte en un "deber nacional" y el Estado debe financiarla, necesariamente se tenía que desembocar en una situación deficitaria de deuda intema y externa. Si a estas abversidades se unen las propias deficiencias técnicas en un proceso de refinanciamiento de la mora -donde la gran empresa privada tiene la mayor parte y arto- debemos deducir que la 
plena culpabilidad no está en la nacionalización bancaria, es decir tampoco la solución definitiva no está en la privatización.

La firma alemana IPC orienta acertadamente la agenda de la reforma estructural bancaria. "Por las consideraciones más bien pragmáticas senaladas, nos parece ventajoso adoptar un régimen funcional y descentralizado para un pais como El Salvador. De ahi que recomendemos, como una importante tarea política de un nuevo gobierno, su introducción e implementación. Es importante subrayar que esta opción normativa no constituye una recomendación "monetaria y ultraliberal", que apunte a reducir al máximo la intervención del Estado en la economia. Al contrario, creemos que precisamente en un país en desarrollo el Estado deberia desarrollar una activa política económica. Sin embargo, para fines de intervención compensatoria, el uso del sistema financiero no resulta apropiado; deben utilizarse otros instrumentos, que resultan más eficientes y menos peligrosos. Asímismo, la opción por un régimen financiero funcional y descentralizado no implica que se plantee la privatización de los bancos. En efecto, la propiedad privada no es una codición necesaria, ni suficiente, para lograr que los bancos se conviertan en intemmediarios financieros relativamente eficientes" ${ }^{\prime 0 . . . " ~}$ En nuestra opinión, el mayor problema actual del marco institucional del sistema financiero de El Salvador, es la falta de un organismo superior independiente, poderoso e eficiente" ${ }^{n} .10$

Por cuanto se conoce, al redactor este comentario, parecerla que no es ésta la línea de ordenamiento de la actual reforma monetaria. Los proyectos de Ley de Reforma visualizarlan en primer lugar articular el proceso de privatización bancaria y el saneamiento de la cartera, dejando para fechas ulteriores normar las funciones controladoras de la Superintendencia de Bancos. Hace más de un ano el presidente del BCR manifestó en conferencia de prensa, su posición de "eliminar la Junta Monetaria, entidad que hasta el momento toma sus decisiones con criterio politico, perjudicando asl a todo el sistema financiero.... Las decisiones de politica financiera debe tomarlas el Banco Central de Reserva, con criterio técnico; y el control efectivo sobre el sistema bancario robustecido se harla a través de la Superintendencia de Bancos" (Diario de Hoy. 11-agosto-1989)"

En una óptica del todo privatizar se corre el riesgo de suprimir, en vez de corregir y adaptar, lo que puede ser el eje orientador del crédito nacional. Con ánimo de corregir-adaptar, en vez de suprimir, nos preguntamos qué aspectos positivos y negativos se han dado en la constitución de la Junta Monetaria. La Junta Monetaria se crea en la década de 1970 cuando el Estado quiere participar más activamente en la rea- 
nimación económica a través del gasto público, y cuando la actividad privada resiste los efectos contractivos de la estanflación mundial y los efectos contractivos que la guerra con Honduras nos generó al interior del istmo centroamericano. Se constituye, desde 1972, como el organismo rector de la política monetaria y crediticia, al mismo tiempo que el gobierno edita un Plan de Desarrollo Económico y Social, (19731977) con ánimo de realizar un conjunto de reformas económicas y sociales. Las circunstancias históricas pueden explicar que la Ley del Régimen Monetario llevara a centralizar en la Junta Monetaria funciones más bien propias de un Banco Central, como son la aprobación del presupuesto monetario, los encajes legales, las tasas de interés, los controles cuantitativos del crédito, el valor externo del colón y las normas aplicables al sistema bancario. Cuando se quiere pasar de un crecimiento a un desarrollo económico y social se aprecian elementos positivos en la composición de la Junta Monetaria, por cuanto los titulares de los ministerios de planificación, economia, comercio, agricultura y hacienda pública estarian calificados para orientar las políticas monetarias hacia el mejor desenvolvimiento de estas áreas claves de la economia privada y pública. El presidente del BCR, en cuanto secretario y codificador de las orientaciones generales y sectoriales, las traduciria, junto con su directorio, en normas y medidas concretas aplicadas por el sistema bancario. Se respetaria, en principio, la autonomía del Banco Central al mismo tiempo que se orienta a quien debe determinar las políticas concretas.

Pasando de la teoría a la historia aparecen los aspectos negativos y el deficiente juego de una estructura de autoridad monetaria conceptualmente buena. Surgió una doble, incluso triple deficiencia. Los miembros de la Junta Monetaria responden a puestos políticos y por ende transitorios como el gobierno de turno que los nombra. La autoridad de que goza el Presidente de la República para nombrar y remover a los miembos de la Junta Monetaria, presidente y vicepresidente del BCR, primer nominado de la Superintendencia de Bancos, sin que la Asamblea Legislativa y otro poder público participen en estas nominaciones, fácilmente pone en peligro la autonomla del Banco Central y de la Superintencia de Bancos, al mismo tiempo que priva de estabilidad y responsabilidad a los miembros de la Junta Monetaria; peor aún si echa a andar la nueda de caballitos. Quienes cumplan con estas funciones del organismo rector y orientador de la politica monetaria deben ser profesionales técnicamente calificados, con probada experiencia y mayor estabilidad en su cargo, no removibles al són de los vaivenes gubernamentales. La complejidad y persistencia de la problemática monetaria nacional e intemacional exige una estabilidad mayor, una cuali- 
ficación técnica (no el parasitismo inerte) y una independencia política, que no se asegura con la actual reglamentación de la Junta Monetaria. Otras instancias deben regular el acceso y la remoción de los miembros del supremo directorio monetario-financiero.

La estructuración monolítica y vertical de la autoridad monetaria generó una tercera deficiencia. Algunos presidentes del Banco Central, en cuanto secretario de la Junta Monetaria, tomaron muy en serio la custodia del secreto. Esto vale sobre todo para anteriores regimenes, cuando el top-secret era la norma de conducta del BCR. Una institución que intregra un elevado número de técnicos bien calificados editaba simplemente la revista mensual y las memorias anuales; todo ello era una contabilidad ex-post y por ciento con bastante retraso. El programa monetario aparecia también con un recatado retraso, y los estudiosos o interesados en los problemas y políticas monetarias debian hacer esfuerzos de imaginación. El resto de estudios preparados al interior del Banco Central eran más bien objetos de exportación con destino a las instituciones internacionales acreedoras, y no tanto para uso y consumo del público nacional. Tampoco el Banco Central puede adjudicarse el papel de suprema autoridad monetaria, cumplir con su función de Banco de la Nación y Banco de Bancos, si la nación y lo bancos son mantenidos en la ignorancia de sus problemas y de sus políticas. La buena autoridad es la puede explicar y razonar to que hace, y la que sabe aceptar los comentarios y críticas. Hay signos escritos de que se quiere enmendar este defecto del pasado; pero queda en pie otro problema.

La persistencia y complejidad de los problemas monetarios, problemas estructurales en nuestro caso, requieren la misma competencia, estabilidad $e$ independencia politica que se ha venido exigiendo a los miembros de la Junta Monetaria. Sin embargo, la designación del presidente y vicepresidente del BCR viene del Presidente de la República, por un perlodo de tres anos con posibilidad de renovación. Los otros cuatro miembros del consejo directivo eran o son elegidos por la Junta Monetaria. La dependencia política o gubernamental de que pudo adolecer la Junta Monetaria puede aparecer con la misma intensidad en la presidencia y directorio del Banco Central. Suele decirse que el presidente del Banco Central debe hacer con frecuencia el papel de "mister niet"=Gromiko (decir "no y no") al ejecutivo y sobre todo al ministro de hacienda; pero su dependencia politica y su posible remoción debilitarlan tal postura de firmeza. Por otra parte, el perlodo de tres anos para la presidencia del Banco Central y la Superintendencia de Bancos es demasiado breve, quedando condicionada la renovación al parecer del Ejecutivo. En resumen, una excesiva concentración de poderes en 
el ejecutivo, que del parecer de la misión alemana IPC no va de acuerdo con las normas establecidas en USA y Europa.

Hablar de independencia politica en los órganos que ejercen la autoridad monetaria no significa, en modo alguno, aislacionismo de las políticas económicas estatales." Al contrario, creemos que precisamente en un pals en desarrollo el Estado debe desarrollar una activa politica económica" (CENITEC; p. 35). Nomalmente los gobiernos establecen sus objetivos en un Plan de Desarrollo; se pueden y se deben cuestionar sus principios ideológicos y las estrategias propuestas. Normalmente estos Planes de Desarrollo suelen dejar planteados los grandes problemas económicos. De un gobierno a otro pueden o suelen cambiar los principios rectores, los mecanismos de funcionamiento o modelo económico; pero los problemas estructurales siguen esperando una solución. La suprema autoridad monetaria, sea cual sea el nombre que recibe, asl como el Banco Central estarán compenetrados de los problemas estructurales y evaluarán los planes propuestos por cada gobiemo. La autoridad monetaria, conjugando la técnica con la independencia, debe promover y catalizar desde su óptica del medianolargo plazo monetario las mejoras estructurales a nivel de nación; debe emiltir su juicio de valor, incluso su oposición, frente a opciones o medidas coyunturales contradictorias con los objetivos del más largo pla$z 0$.

Esto requiere una reestructuración de la cúpula monetaria, quedando en discusión si la Junta o Directorio Monetario se transforma en el Directorio del Banco Central, o si permanece como institución aparte, con sus funciones de orientación y consultorla. En ambos supuestos el Banco Central adoptarla las medidas prácticas y concretas que hasta el presente detallaba la Junta Monetaria." Se lograrla un contrapeso institucional más adecuado entre un ejecutivo, que tiende necesariamente a privilegiar los aspectos del corto plazo, y un Banco Central, que debe considerar sobre todo los intereses de mediano y largo plazo del desarrollo nacional, asl como defender la estabilidad monetaria y crediticia" (CENITEC; p.11)

Si hace más de un ano el Presidente del BCR, Ing. Roberto Orellana Milla, proponla que el control efectivo se ejerciera por la Superintendencia de Bancos, también la firma alemana IPC apoya con mayor énfasis la propuesta." En nuestra opinión el mayor problema actual en el marco institucional del sistema financiero de El Salvador es la falta de un organismo supervisor independiente, poderoso y eficiente (CENITEC; p. 41) Los tres calificativos refuerzan la recomendacióm, luego del análisis de la sobregirada mora, la reducida rentabilidad y las insuficien- 
tes reservas propias (ibidem; pp. 23-29). La postdata a la recomendación también es importante: fortalecer el control no significa privar de iniciativa el sistema bancario o desterrar todo riesgo. Debiendo estar presente el criterio de rentabilidad bancaria, la experiencia de otros paises y del nuestro ensenan que no es cierto que los pequenos créditos generen riesgos inaceptables, sino más bien to han sido los grandes créditos, concodidos a prestatarios influyentes del área politica o económica. Esto último es lo que ha generado la pérdida de confianza de los depositantes en el sistema bancario.

La quiebra de un banco genera un multiplicador del pánico en el conjunto bancario; pero los sistemas de contabilidad pueden disimular y postergar semejante estallido. La posible solución de última instancia, por este u otros motivos de escala financiera, serla la fusión o la absorción; pero es preferible poder aplicar a tiempo las medidas preventivas por parte de la Superintendencia de Bancos. Sus poderes de su. pervisión y control deben extenderse a la facultad y posibilidad de cemar un banco cuando sus depositantes están amenazados (ibidem; $\mathbf{p}$. 39). La amenaza, unida a la posibilidad de cierre, será un aliciente para la buena gestión de los bancos privados y nacionalizados. Se normalizarán los parámetros de liquidez, solvencia y rentabilidad, las relaciones entre patrimonio y activo, el crédito máximo por cliente como porcentaje de patrimionio de la institución bancaria. Ello requiere que la Superintendencia de los Bancos tenga acceso libre y autorizado a las auditorlas intemas bancarias. La supervisión debe extenderse a la calificación de los directivos, su experiencia profesional y su integridad, evitando que la gestión bancaria obedezca a criterios políticos en el nombramiento de los altos ejecutivos.

Para ejercer estas funciones se requiere que "la institución supervisora tenga una autonomia legal y presupuestaria frente al gobiemo y al Banco Central, ya que si esta institución ejerce debidamente sus funciones, se encontrará casi automáticamente en conflicto con estos ültimos, especialmente con el gobierno. La Superintendencia de la Banca debe dar cuenta de sus acciones al Parlamento, sin cuya aprobación no podrá ser removido su jefe" (ibidem; p. 41). Por lo tanto, su presupuesto no debe depender del BCR, sino de una contribución directa de los propios bancos.

\section{Crédto soclal con capltal prlvado}

Lo hasta aqul expresado y más bien recomendado por expertos extranjeros muestra que el mercado de dinero es un "mercado politizado" por cuanto debe reformularse en su cujpula y en sus instituciones 
de base en orden a lograr, en la medida posible, el crédito social y la estabilidad monetaria. Hablamos de mercado monetario al servicio del mercado de bienes y servicios. Aqul surge un problema: el primero es un mercado politizado, el segundo puede ser un libre mercado. $Y$ es el propio término de "mercado" el que está en cuestionamiento. Una forma de expresarlo es que hablamos indistintamente de "Yuerzas del mercado y de leyes del mercado." La primera expresión da a entender un enfrentamiento de fuerzas que derivarian hacia un darwinismo social; la segunda expresión aconsejarla una regulación del mercado para que las fuerzas no sean el regulador de las relaciones sociales. En otras palabras, ni las fuerzas deben convertirse en leyes, ni las leyes ser las fuerzas. Este es el problema de relaciones entre el mercado real y el mercado monetario.

Un comentariu, referido a un pais ajeno pero en el centro de la vitrina, nos puede ayudar a una reflexión bien cercano a nuestro caso. EI Dr. Julio S. Ramírez, Director del Programa de Master del INCAE, comenta asl el fenómeno del Este-europeo." No deja de ser inquietante notar que un número considerable de analistas a nivel mundial interpretan el fenómeno del desplome del orden político leninista-stanlinista en la URSS y en su área de dominio en Europa solamente como el triunfo del mercado. Es indudable que las enormes fallas generadas por la planificación central, como método básico de asignación de recursos, han tenido enorme peso en ese descalabro. Es preocupante que esa causa sea percibida por muchos intelectuales en Occidente como la más transcendental o la única de importancia, pues podría llevarnos a conclusiones equivocadas, entre ellas al endiosamiento del mercado, tomándolo como el medio ideal y pertecto para la asignación de recursos en la sociedad. Existen pocas dudas de que el mercado puede ser un excelente medio para la asignación de recursos eficiente y beneficiosa desde el punto de vista de la sociedad como un todo, siempre y cuando se den algunas condiciones, entre las cuales podemos mencionar dos de especial relevancia hoy: que la distribución de ingreso y riqueza existente en la sociedad sea considerada como aceptable, y que no existan efectos secundarios (externalidades) de importancia que pudiesen ser ignorados por los consumidores o por los productores al tomar sus decisiones. Es abundante la evidencia acerca de las fallas del mercado para producir las señales correctas en muchas circunstancias de ocurrencia cotidiana, para poderla ignorar y deificar el mercado... El progreso ha incrementado nuestras capacidades productivas de manera considerable, permitiendo mayores niveles de consumo y disfrute material de la vida; desafortunadamente el progreso no ha incrementado de manera similar nuestra capacidad de autocontrol, modera- 
ción de nuestros hábitos y solidaridad con nuestros semejantes, poniéndonos al borde del abismo de nuestra propia dignidad, si insistimos en construir una forma de vida inspirada en el más acaramelado materialismo hedonista. El progreso ha incrementado nuestras capacidades para mejorar la vida y la civilización. Pero, desafortunadamente, el progreso también ha incrementado nuestra capacidad individual y colectiva para destruir la vida y la naturaleza e infligir sufrimientos a otros". ${ }^{12}$

Esta cita - algo extensa - asi como el excelente articulo firmado por este doctor de Harvard resumen brillantemente el problema congénito del mercado: fuerzas y leyes, rentabilidad y solidaridad, capital privado y crédito social. Cuando decimos que el sistema bancario va a obedecer las orientaciones del mercado, nos preguntamos: ¿al de la rentabilidad $o$ al de la solidaridad?; ¿como hacer para que conjugue los dos servicios?

Nuestro Plan de Desarrollo plantea este mismo problema. Con terminologia más o menos afortunada, nuestro plan se divide en dos partes. La primera: "Plan de Desarrollo Económico", distribuido en seis acápites, precedidos por los principios filosófios de una economía de mercado. ${ }^{13}$ Este seria eminentemente el imperio del mercado y del sector privado, apoyado por un plan de inversiones públicas. A la segunda parte se le da el nombre de Plan de Desarrollo Social, subimperio delegado esencialmente al sector público o Estado, con la recomendación de mantener un papel subsidiario, pero to subsidiario o compensación social, integra las siguientes áreas: la educación, la saludnutrición, la vivienda, la familia, la previsión social, el empleo de la fuerza laboral, la ecología. Esta división, no muy afortunada, plantea consciente $o$ inconscientemente el problema de nuestro mercado real y monetario. Plantea un interrogante teórico: saca de la esfera del Desarrollo Económico lo que es la base fundamental del mismo desarrollo económico. Asi como es muy acertado calificar de desarrollo social a las siete áreas mencionadas, por cuanto afectan la suerte de la mayoria social o mayorias populares, no es muy acertado desligarlas del mercado económico, que no podrá desarrollarse en forma sostenida sin el otro desarrollo social. Volvemos al problema de un mercado dual, que 10 pone de manifiesto el mismo Plan de Desarrollo. Es la diferencia entre trabajar y evaluar la economía con cifras macroeconómicas (de crecimiento) o en términos de solidaridad humana (de desarrollo económico). Si tal es el dilema del mercado de bienes y servicios, este mismo será el dilema del mercado monetario que debe afrontar la reforma general del sistema bancario. Privatización-estatización son simples modalidades de organización bancaria, por cierto no contrapuestas, que deberán integrarse en una sana simbiósis para hacer de las dos partes, 
la económica y la social, un sólo plan de desarrollo.

\subsection{Los criterlos del crédito}

Ya han quedado descartados los criterios de politización del crédito típicos de la década de $1980 \ldots$... (politización partidista-gubernamental) y de las décadas anteriores a 1980 (politización de propietarios: al que tiene se le dará). Para corregir la primera politización se busca desregular la intromisión gubernamental, con verdadera autonomia de la autoridad bancaria. Para corregir la segunda politización se programa una estricta normativa de saneamiento de cartera, distribución de acciones constitutivas del patrimonio bancario, con severos controles de parte de la Superintencia de Bancos (Boletines Económicos del BCR1990). Es interesante conocer que los grandes morosos no podrán formar parte de los directorios bancarios, siempre que la confidencia bancaria no resultare tan confusa como la confidencialidad judicial.

Precisamente el tema de la mora y su correlato la insolvencia bancaria nos lleva a reflexionar sobre los criterios que orientarán al crédito. Es lógico y totalmente necesario que el proceso de saneamiento de cartera lleve a prestar especial atención al criterio de la rentabilidad, de cara a los posibles accionistas, a la seguridad de los depositantes y la necesidad de reconstruir el patrimonio bancario. La lógica del proceso va de la rentabilidad bancaria a la consolidación de estas instituciones para ejercer más eficientemente su intermediación financiera. La rentabilidad bancaria surgirá de la rentabilidad monetaria de los proyectos a financiar, la cual a su vez depende de que en el mercado se esté trabajando con precios oligopólicos, precios administrados a no discutir o precios deprimidos. Una vez más un necesario criterio de rentabilida monetaria puede entrar en conflicto con un criterio social: rentabilidad versus solidaridad. Es el temor que se expresa en la pregunta: ¿rentabilidad y crédito, para quién?

Una forma de reflexionar sobre este criterio de rentabilidad es enmarcarlo dentro de otros criterios de rentabilidad y eficiencia social. Es claro que el Plan de Desarrollo busca un proceso combinado de reactivación económica y de generación de empleo; esto conduciria a una elevación general del ingreso y, bien llevado, a una mejor distribución de los ingresos en plural. Un crédito que obedeciera a estos criterios generaria una rentabilidad social y tendria tanto mayor impacto en el empleo y en la reactivación cuanto más directamente favoreciera a aquellas ramas y sectores que, a su vez, desencadenaran una secuencia de efectos directos e indirectos sobre el conjunto estructural de toda la economia. Bajo esta optica, el multiplicador del crédito $(K=1 / E . L$.) 
estarla al servicio del multiplicador de la inversión o reactivación económica $\left(k=1 / 1-c^{\prime}\right)$. A este fin se utilizan las matrices intersectoriales para orientar y maximizar el efecto multiplicador del crédito y de la inversión, aplicando el análisis a las exportaciones tradicionales y no tradicionales asl como a los productos-servicios de uso interno. Esta secuencia o encadenamiento de efectos directos e indirectos sobre el conjunto económico hace que el sistema bancario sea un buen intermediario financiero y asegure su propia rentabilidad monetaria. Se trata de combinar la rentabilidad bancaria con la rentabilidad social.

En espera de que el Departamento de política Económica del BCR actualice la Matriz Insumo-Producto-1984, sigue teniendo plena vigencia a este fin, la matriz editada en 1986 y referida a la economía de 1978. Dado que una matriz intersectorial detalla la estructura técnica de producción se mantienen relativamente estables los elementos componentes de la producción de cada rama-sector, aunque hayan podido variar algo los respectivos coeficientes técnicos o costos porcentuales de producción, en razón de la coyuntura interna e intemacional. Una revisión de nuestra matriz monetaria insumo-producto pudiera orientar a las autoridades del sistema bancario para que ellas, a su vez, orienten el crédito hacia una mayor generación de empleo y de reactivación económica. Por esta razón, como ejemplo resumido, se reproduce el cuadro que lista los 15 sectores respectivamente más importantes desde cuatro puntos de vista: el valor bruto de la producción; sectores claves o dinamizantes como demandantes de insumos; sectores dinamizantes como oferentes de insumos y por el valor-agregado. Este cuadro se reprodujo en anterior ocasión ${ }^{14}$ a propósito del terna de la Economla Social de Mercado.

Las cuatro clasificaciones son importantes para un análisis y planeación económica. En orden a lograr un crédito dirigido a la generación de empleo y reactivación económica son más significativas las dos columnas centrales, que listan los sectores dinamizantes como demandantes y oferentes de insumos respectivamente. También se pudiera descomponer, dentro de la partida de sueldos salarios del Valor Agregado, aquellas remuneraciones laborales más reactivantes por tener mayor propensión marginal a consumir, $\left(k=1 / 1-c^{\prime}\right)$.

Estas dos columnas centrales son bien iluminadoras para la autoridad polltica y monetaria si desean alentar un crédito de rentabilidad social; en otras palabras si realmente se pretende integrar en un sólo Plan de Desarrollo la vertiente económica y la vertiente social. Es innegable que ambas columnas nos indican un conjunto de ramas-sectores más dinamizantes o reactivante de la economia, y en principio más ge- 


\begin{tabular}{|c|c|c|c|}
\hline $\begin{array}{l}\text { Sectores importantes por } \\
\text { el valor-bruto-de su produc- } \\
\text { ción. }\end{array}$ & $\begin{array}{l}\text { II) Sectores dinamizantes co- } \\
\text { mo demandantes de insu- } \\
\text { mos. En columna de matriz. }\end{array}$ & $\begin{array}{l}\text { III) Sectores dinamizantes co- } \\
\text { mo oferentes de insumos. En } \\
\text { la fila de la matriz. }\end{array}$ & $\begin{array}{l}\text { IV) Sectores importantes por } \\
\text { el valor agregado. Renumera. } \\
\text { ción a factor. }\end{array}$ \\
\hline 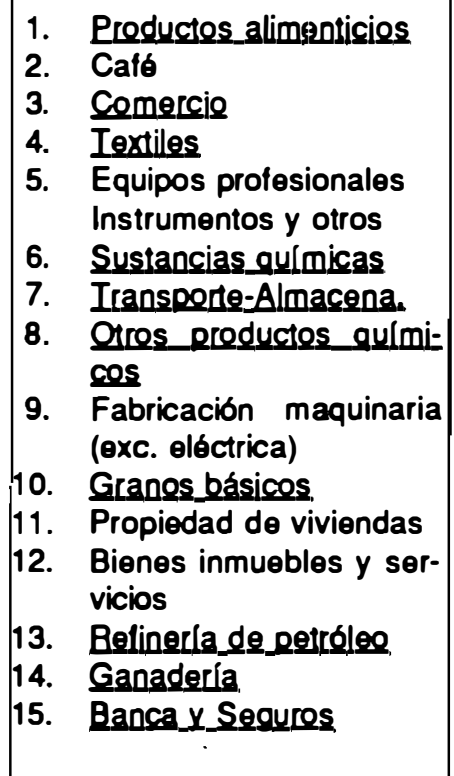 & 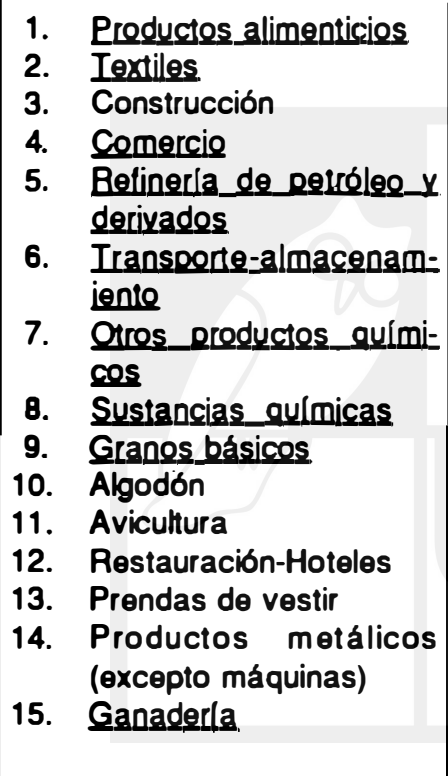 & 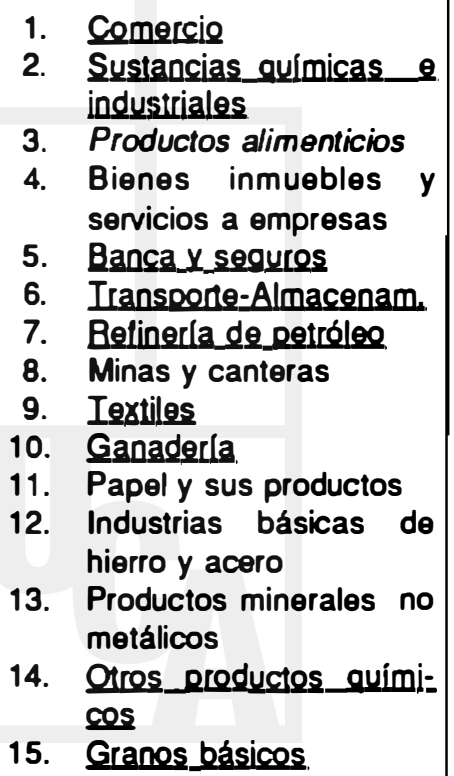 & 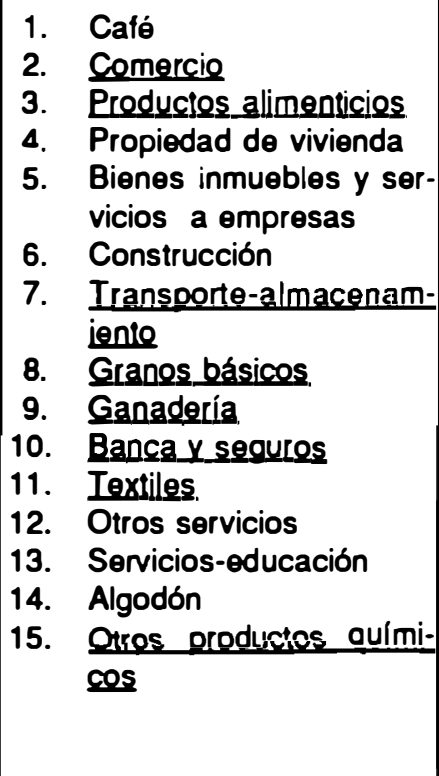 \\
\hline
\end{tabular}

Fuente: Matriz insumo-producto-1978, de la Economla Salvadoreña. (Primera edición). BCR. 
neradores de empleo, al demandar y ofrecer respectivamente más insumos a mayor número de sectores productivos. Una anécdota económica resulta bastante iluminadora. Preguntado $W$. Lenntief sobre el uso que se habia dado a sus matrices intersectoriales el premio-Nobel respondió que en Europa se las habia utilizado más bien para orientar la planeación económica; en EE.UU. es donde más se habian perfeccionado, pero quien más la habia utilizado era la gran empresa para controlar los sectores más dinamizantes de la economia. No sin razón K. Galbrait deduciria que la economia norteamericana está planificada por la gran empresa. Algo de eso pasa en nuestro país.

Sin embargo es otro el comentario pertinente en la línea de los criterios orientadores del crédito. Resulta que la mayoria de estos sectores más dinamizantes de la economia responden o pudieran responder a la satisfacción de las necesidades básicas o canasta familiar: granos básicos, productos alimenticios, textiles-vestuario, construcciónvivienda, misceláneos quimicos.... La mayoria de estos sectores económicos dinamizantes pudieran dar una cercana respuesta a aquellas siete áreas, que el Plan de Desarrollo clasifica como "compensación social". Si a los quince sectores listados anadimos que, de cuerdo a la matriz (en su primera edición de 49 ramas) la educación demanda insumos de 37 sectores y los ofrece a 14 ramas, mientras que los servicios médicos demandan insumos de 38 sectores y los ofrecen a otros 10. podemos concluir que un crédito sensiblemente dirigido a esas siete áreas del desarrollo social se traduciria en un crédito dinamizante y al mismo tiempo de elevada rentabilidad social. Esto vendria a unificar las dos partes del plan en un sólo Plan de Desarrollo conjugando la rentabilidad social con la suficiente rentabilidad monetaria. Esta tesis quedó confirmada con una investigación centrada en el tema de las necesidades básicas y la reactivación económica. ${ }^{15}$ Este trabajo muestra el efecto multiplicador del crédito-inversión sobre el PTB, la generación de empleo, los ingresos laborales, y empresariales y la demanda externa de importaciones requeridas. Esto nos devuelve al tema de los criterios orientadores del crédito en la reforma bancaria: ¿cómo hacer la simbiósis de la necesaria rentabilidad monetaria y de la más necesaria remtabilidad social o reactivación económica.

La actual crisis del petróleo puede convertirse de hecho coyuntural en situación estructural con un doble efecto: alza de precios del crudo y sus múltiples derivados, aunado a una escasez de divisas con incremento de la deuda externa. El gobierno no es culpable de tal imprevisto exógeno, como no lo fueron los gobiernos de 1973 y 1979. Pero el gobiemo, entendido aqul como la autoridad política y la autoridad monetaria, tienen que enfrentar este severo contratiempo. No basta 
aconsejar que la población tome ciertas medidas de precaución para ahorrar combustible. El problema se convierte en dato estructural: un problema de ahorro de divisas y de selección de importaciones. Se impone revisar el criterio de liberación de importaciones. Incluso, sin este contratiempo, en un pais de elevada pobreza interna y crecida deuda externa se impondria un severo proceso de selección de importaciones. Ahora, la crisis del petróleo reduplica esta priorización. No todas las importaciones permisibles encajan en nuestro entorno, ni son objetivamente beneficiosas. También a este efecto las matrices intersectoriales nos indican suficientemente cuáles son las importaciones claves en cuanto representan los suministros del mayor número de ramas productivas.

Esta presión externa, gestada en la crisis del petróleo, que de temporal se transformará o la transformaremos en permanente, impone reconsiderar los criterios del control y del crédito de las divisas. El criterio de la rentabilidad monetaria fácilmente se traducirá en priorización de importaciones relativamente innecesarias o suntuarias. Tan importante como regular el régimen de propiedad privada del patrimonio bancario resulta el normar los criterios de rentabilidad del crédito en moneda nacional y en divisas externas. Liberalizar y ceder a las fuerzas del mercado nos puede llevar a una desintegración del mismo mercado. Cuando, en situación de crisis, se deja que el mercado controle el propio mercado cada cual busca sus propias ventajas: el mercado es corto de vista para mirar la rentabilidad social. No sería de extranar que, pese a todas las exhortaciones patrióticas, las empresas y comercios se afanen por traspasar a los precios finales un efecto multiplicado del costo del petróleo y sus derivados; y el gobierno se veré entonces forzado a enfrentar y tratar de controlar las consecuencias políticas. Por lo menos tenemos que admitir que nos hallamos inmersos en una atmósfera de desintegración y descontrol que vuelve a poner en peligro el criterio de rentabilidad social e incluso la propia rentabilidad bancaria del mediano plazo se torna bastante aleatoria. El "laissaez-fairen del mercado es tan cómodo en el corto plazo como incómodo socialmente en el mediano plazo para el mismo gobierno.

\subsection{Un control sin control}

No se trata de un juego de palabras sino de la compleja realidad que parecería combinar zonas muy controladas con amplias esferas libres de control. A mediados de septiembre el Ministro de Economía se manifestó opuesto al control de precios por parte del Estado, afirmando ser ésta la tarea del juego de la oferta y demanda del mercado. Esta aseveración la hizo a los dias de que el gobiemo estableciera un con- 
trol estricto de los precios de la gasolina-super, la regular, el diessel... y otros derivados del petróleo, de manera que unos precios administrados, a no discutir, subvencionaran a otros precios por razones sociales. Toda regla admite sus excepciones; el problema está en quién establece la regla y las excepciones. De todas formas, implicitamente se admite que el juego del mercado no es la guia universal de la fijación de precios y que, a veces, se imponen los controles. Surge la pregunta, ¿cuándo y en qué hay que aplicar controles legales y qué se puede relegar a las fuerzas del libre mercado?

Precisamente los anteproyectos de saneamiento y privatización bancaria nos dan base a reflexionar sobre esta pregunta. Se va a controlar la propiedad del patrimonio bancario de suerte que ningún accionista, persona natural o juridica, puede sobrepasar el $5 \%$ del patrimonio de la institución. Obviamente la razón de este control no es ideológica o partidista, posible defecto de los anos 1980 ... Si tal fuera la razón, el anteproyecto de ley prohibiria que cualquier partido político o asociación gremial acumulara más del $5 \%$ de las acciones de cada institución. La ley no prohibe esto último, aunque es lógico presuponer que si el $90 \%$ de los accionistas fueran miembros de determinada facción politica presionaria a la directiva del banco para preferenciar los créditos de los propios simpatizantes; tendriamos asi otro tipo de competencia bancaria, que la actual ley no lo prohibe y distinguiriamos a los bancos de acuerdo a sus colores. Esto significa que el anteproyecto de ley ve otro peligro mayor que el de la politización partidista. $Y$ ese peligro mayor es la desmesurada concentración de propiedad en pocas manos. En otras palabras se admite que la desmesurada propiedad privada o concentración del accionariado es un elemento perturbador de los objetivos sociales del mercado monetario.

Lo extraño es que éste o semejante argumento no se aplique a la concentración de propiedad en el mercado real de la producción. Se controla uno y se deja fuera de control el otro. El problema del "control sin control" surge del hecho que el sistema bancario controlado debe servir y seguir las indicaciones del sector real no controlado. Se estaria trabajando con dos hipótesis diferentes. Conviene controlar por la ley la concentración de la propiedad bancaria porque puede darse y si existe es pemiciosa para la intermediación financiera social. No se controla en forma semejante al sector real empresarial porque se supondrla que aqul no se da tal concentración de propiedad privada, o si se diera no derivarla hacia una producción antisocial. No se utilizan bien las hipotesis para aplicar el control y sobre todo para no aplicar los controles. 
De manera más explícita la legislación actual destierra del patrimonio bancario a la participación estatal. Pueden ser propietarios los empleados, los inversores naclonales y los inversores extranjeros en sus respectivos bancos. Se quiere evitar en forma tajante la politización y abuso gubermamental del crédito. Queda, con todo, un interrogante ya que la ley hace referencia a la banca nacional, a la banca extranjera, pero no a la banca estatal. Sin embargo, hay momentos y razones históricas que han hecho imprescindible la banca estatal, con fines y objetivos determinados, cuando la banca privada deja desatendidas aquellas áreas sociales que el propio Plan de Desarrollo encomienda al Estado, o la múltiple pequena empresa incapaz de ofrecer las garantlas de regla. No es éste el único interrogante que nos deja la prelectura del anteproyecto de ley de saneamiento y privatización bancaria.

En dicho proyecto hay referencias explicitas a la Superintendencia del Sistema Bancario, aunque falta especificar, en un tercer ante proyecto, sus funciones, su estructuración y sus atribuciones respecto al Banco Central, además de las tareas de vigilancia y control del conjunto de instituciones financieras. No hay referencia alguna a la Junta Monetaria; ¿se suprime, se corrige, queda integrada en el directorio del Banco Central? De momento el BCR, es decir su presidente, nombrarla al presidente y dos directores, con sus suplentes, de cada institución bancaria. Esta concentración del poder en los nombramientos corre el riesgo de convertirse en una selección aleatoria, si al mismo tiempo la ley no determina los requisitos de competencia técnica, experiencia y honorabilidad comprobada exigibles en tales puestos directivos, como se hace en otros paises. De lo contrario puede pesar mucho el parentesco ideológico o partidista sobre las otras cualidades mencionadas.

Hay un detalle positivo en el proceso de privatización bancaria y es la coparticipación de acciones ofrecidas a todos los empleados. Se busca con ello una integración del capital y del trabajo en cada institución; este capitalismo popular estimulará la eficiencia y creatividad de los propios empleados. Precisamente es esta integración de capital y trabajo la que pretenden lograr las cooperativas del sector reformado y tradicional. Si por ley se alienta esta integración en el nuevo sector bancario también convendrla alentar y no frenar, por medios directos e indirectos, los esfuerzos ya avanzados en el amplio sector cooperativo. Más aún, si en la óptica de la privatización bancaria se pretende corregir la concentración de propiedad con la coparticipación del trabajo en el capital, ¿no serla ésta la línea a seguir en el amplio sector de la empresa privada productiva?. Los argumentos tendrlan igual relevancia en el sector real de la producción, convirtiendo al mercado en lo que el 
Plan de Desarrolo llama una "democracia económica" en acción. Claro que esto requerirla presentar a la Asamblea Legislativa un proyecto de "Ley de Privatización de la Empresa Privada". Sin duda aqul nos enfrentarlamos con dos lecturas bien diferentes del primer postulado $\theta 00$ nómico de nuestro Plan de Desarrollo:" La propiedad privada es condición necesaria para la eficiencia de la producción... La propiedad privada es un derecho inalienable del ser humano, que estimula el uso eficiente de los recursos y del desarrollo económico y social de una nación". Leyendo en línea recta este postulado nos dice que no hay efisiencia de producción, ni buen uso de recursos, ni siquiera ser humano posible sin una inalienable propiedad privada. En esta misma optica el proceso de privatización bancaria deberla extenderse a una coparticlon del capital-trabajo en el sector real de la producción.

De momento, este anteproyecto no ha sido presentado a la Asamblea Legislativa y sigue en pie el problema de "un control sin control". Tendremos un régimen de propiedad privada controlada al servicio de otro régimen de propiedad privada no tan controlada; un mercado politizado del dinero al servicio de un mercado de producción orientado por las fuerzas de la oferta y demanda sectoriales. Con ello el problema de la intermediación financiera tranciende al nivel superior de la dirección y administración bancaria, que trabaja con dinero y depósitos ajenos. La Ley de Privatización regula la composición del patrimonio, fija topes máximos a los créditos internos concedidos al personal de cada institución y techo máximo o porciento del patrimonio en los créditos externos a terceros prestatarios. Sin embargo, entre to controlado y lo no controlado por la la ley queda un amplio espacio: ¿quién y cómo se orientará al crédito del régimen bancario de suerte que se conjugue el criterio de rentabilidad institucional con el criterio de rentabilidad social y reactivación económica?. Queda pendiente el cuestionamiento de la privatización para reforzar la privatización o de la privatización para conseguir el crédito social.

\section{Notas}

1) DIES-CENITEC: "El sistema financiero de El Salvador; análisis y perspectivas". CENITEC. Año-19. Mayo-1989.

2) Arévalo Damas A. R. et alii: "Análisis comparativo de la banca privada y banca nacionalizada on El Salvador: 1971-1988". Tesis de Grado. UCA. Septiembre-1990

3) Idem: pp. 95-102.

4) DIES-CENITEC; opus. cit .; pp. 27-28.

5) BCR, Memoria del BCR-1989; p. 33.

6) Arévalo D. A. R. et alli; opus cit.; p. 47. 
7) Ibidem; p. 48.

8) Ibidem; p. 60.

9) DIES-CENITEC; P. 35.

10) Ibidem; p. 41.

11) Ibisate Fco. Javier. "A los cien dlas de gobierno: ¿hacia dónde vamos?" La privatización del sistema bancario. ECA. Agosto-Sept. 1989 pp. 658...

12) Ramirez Julio S.: "La contrarevolución soviética". Revista INCAE. vol. IV?. No-1; 1990; pp. 83-84.

13) Ibisate FCO. Javier: "El programa de ajuste estructural: una herencia diflcil". Realidad Económica y Social. Dpto. Economla-UCA; mayo-junio 1990; pp. 229...

14) Ibisate Fco. J.: "Economla Social de mercado y economla social $\infty$ mercado". ECA. Abril-mayo, 1989; pp. 311-336.

"El modelo económico salvadoreño en la matriz insumo-producto 1978". Boletin de CC. Económicas y sociales. Sept. Oct. 1986; pp. 264.

15) Orellana Albama.: "Necesidades básicas y reactivación económica". Trabajo de graduación. UCA. Julio-1987. Un compendio de la tesis aparece en Boletl'n de CC. Económicas y Sociales. Julio-Agosto-1987. 